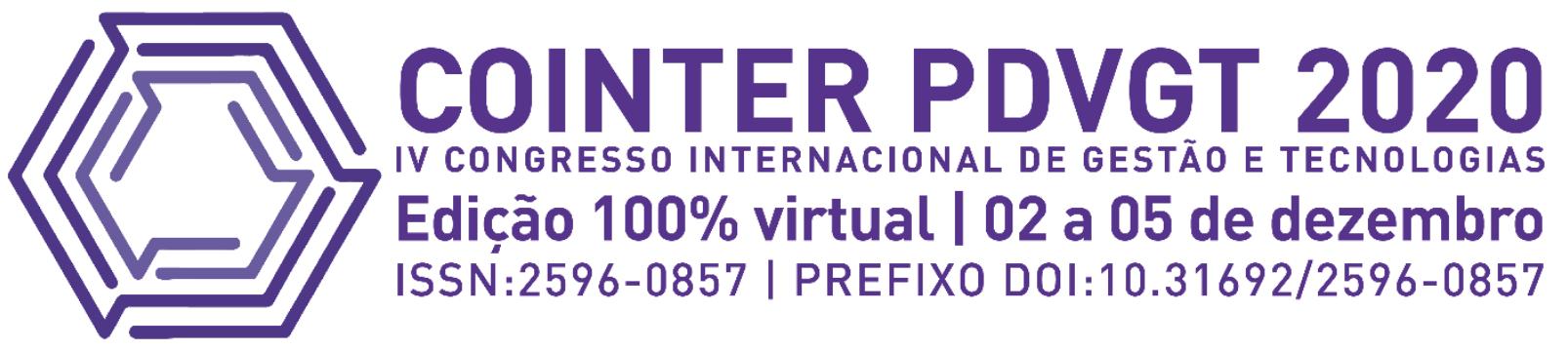

\title{
PRESENÇA DE CONTEÚDOS DE EDUCAÇÃO EMPREENDEDORA NO CURSO DE SEGURANÇA DO TRABALHO
}

\author{
PRESENCIA DE CONTENIDOS DE EDUCACIÓN EMPRENDEDORA EN EL \\ CURSO DE SEGURIDAD LABORAL
}

\section{PRESENCE OF ENTREPRENEURIAL EDUCATION CONTENT IN THE WORK SAFETY COURSE}

\author{
Apresentação: Comunicação Oral \\ Mariana Almeida Ferreira Lima ${ }^{1}$; Amanda Caroline Ribeiro da Costa ${ }^{2}$; Jonathan Érik Nascimento da Silva ${ }^{3}$ \\ Larissa Amanda Pereira da Silva ${ }^{4}$; Erick Viana da Silva ${ }^{5}$
}

DOI: https://doi.org/10.31692/2596-0857.IVCOINTERPDVGT.0108

\begin{abstract}
RESUMO
Os sistemas educacionais, historicamente são moldados visando uma formação profissional específica, e com metodologias de "transmissão" de conteúdos, deixando de estimular o pensamento crítico do estudante e a busca por aplicações práticas. Todavia, é observada uma crescente tendência das organizações de buscarem contratar funcionários de atitude empreendedora, portanto, é necessário que a escola prepare os estudantes para atender às demandas de mercado. Dessa forma, a inserção da educação empreendedora nos diferentes níveis de educação é fundamental, salientando também para a importância do uso de metodologias ativas na educação para - e não sobre - empreender. O objetivo dessa pesquisa é identificar a presença de conteúdos de educação empreendedora em um Campus do IFPE. Para tanto, utilizamos de uma pesquisa de caráter exploratório, descritivo e de campo, cujos sujeitos foram os docentes da área de Gestão que atuam no Curso Técnico em Segurança do Trabalho e os estudantes do Curso Técnico em Segurança do Trabalho do Campus escolhido, e o Campo de pesquisa é, por conveniência, o IFPE - Campus Recife. Salientamos, dentre nossos principais resultados, para a identificação de algumas iniciativas de fomento ao empreendedorismo dentro do Campus - como o Ciclo de Palestras "A Gestão no Todo", o Programa Internacional Despertando Vocações (PDV), o Programa Institucional de Bolsas de Iniciação Científica e o núcleo de empreendedorismo - e para a importância do uso de metodologias ativas e atividades extracurriculares apontada pelos estudantes. É, dessa forma, fundamental o apoio e incentivo para o desenvolver das atividades já existentes, bem como a inserção de novas iniciativas na área.

Palavras-Chave: educação empreendedora; metodologias ativas; empreendedorismo; Segurança do Trabalho.
\end{abstract}

\section{RESUMEN}

Los sistemas educativos se han configurado históricamente con miras a una formación profesional

\footnotetext{
${ }^{1}$ Curso Técnico em Edificações, IFPE, marianaalmeidagastro@outlook.com

${ }^{2}$ Curso Técnico em Eletrônica, IFPE, amandacrc326@gmail.com

${ }^{3}$ Curso Técnico em Eletrônica, IFPE, jonathan753_21@ hotmail.com

${ }^{4}$ Curso de Gestão de Turismo, IFPE, larissaamanda05@gmail.com

${ }^{5}$ Mestre em Administração, IFPE, Erick.viana@ recife.ifpe.edu.br
} 
específica, y con metodologías de "transmisión" de contenidos, sin estimular el pensamiento crítico del estudiante y la búsqueda de aplicaciones prácticas. Sin embargo, existe una tendencia creciente de las organizaciones a buscar contratar empleados con actitud emprendedora, por lo que es necesario que la escuela prepare a los estudiantes para satisfacer las demandas del mercado. Así, la inserción de la educación emprendedora en los diferentes niveles educativos es fundamental, enfatizando también la importancia de utilizar metodologías activas en la educación para - y no sobre - emprender. El objetivo de esta investigación es identificar la presencia de contenidos de educación emprendedora en un Campus IFPE. Para ello se utilizó una investigación exploratoria, descriptiva y de campo, cuyos temas fueron profesores de Gestión que laboran en el Curso Técnico en Seguridad Laboral y estudiantes del Curso Técnico en Seguridad Laboral del Recinto elegido, y el El campo de investigación es, por conveniencia, el IFPE - Campus Recife. Destacamos, entre nuestros principales resultados, por la identificación de algunas iniciativas de fomento del emprendimiento dentro del Campus - como el Ciclo de Conferencias "Gestión en su totalidad", el Programa Internacional Despertar Vocaciones (PDV), el Programa Institucional de Becas de Iniciación Científica y el núcleo de emprendimiento - y por la importancia de utilizar metodologías activas y actividades extraescolares señaladas por los estudiantes. Es, por tanto, fundamental apoyar e incentivar el desarrollo de las actividades existentes, así como la inserción de nuevas iniciativas en la zona.

Palabras Clave: educación empresarial; metodologías activas; emprendimiento; Seguridad del trabajo.

\begin{abstract}
Educational systems have historically been shaped with a view to specific professional training, and with methodologies for "transmitting" content, failing to stimulate critical student thinking and the search for practical applications. However, there is a growing tendency of organizations to seek to hire employees with an entrepreneurial attitude, therefore, it is necessary for the school to prepare students to meet market demands. Thus, the insertion of entrepreneurial education at different levels of education is fundamental, also emphasizing the importance of using active methodologies in education for - and not over - undertaking. The objective of this research is to identify the presence of entrepreneurial education content on an IFPE Campus. For that, we used an exploratory, descriptive and field research, whose subjects were Management professors who work in the Technical Course in Workplace Safety and students in the Technical Course in Workplace Safety of the chosen Campus, and the The research field is, for convenience, the IFPE - Campus Recife. We highlight, among our main results, for the identification of some initiatives to foster entrepreneurship within the Campus such as the Cycle of Lectures "Management in the Whole", the International Program Awakening Vocations (PDV), the Institutional Program for Scientific Initiation Scholarships and the entrepreneurship nucleus - and for the importance of using active methodologies and extracurricular activities pointed out by students. It is, therefore, essential to support and encourage the development of existing activities, as well as the insertion of new initiatives in the area.
\end{abstract}

Keywords: entrepreneurial education; active methodologies; entrepreneurship; Workplace safety.

\title{
INTRODUÇÃO
}

No tópico VIII do artigo $6^{\circ}$ da seção II da Lei 11.892, de 29 de dezembro de 2008, Lei que institui a Rede Federal de Educação Profissional, Científica e Tecnológica, é estabelecido que os Institutos Federais de Educação, Ciência e Tecnologia têm dentre suas finalidades e características de "realizar e estimular a pesquisa aplicada, a produção cultural, o empreendedorismo, o cooperativismo e o desenvolvimento científico e tecnológico"(BRASIL, 2008). No que concerne ao empreendedorismo faz cumprir a normativa com a inserção da disciplina de empreendedorismo em todos os cursos técnicos ofertados. 
O profissional de Segurança do Trabalho tem por atribuição zelar pelo cumprimento das diretrizes estabelecidas para execução de determinada atividade profissional e, com isso, evitar a ocorrência de acidentes de trabalho e outros agravos decorrentes do exercício da atividade. O Instituto Federal de Pernambuco oferta o Curso Técnico em Segurança do Trabalho em dois de seus Campi: Recife e Caruaru, nas modalidades Subsequente e Ensino Médio integrado ao Técnico. Dessa forma, em ambos está presente a disciplina de empreendedorismo, e também a disciplina de Relações Humanas e Trabalho, que aborda temáticas semelhantes, inclusive o próprio empreendedorismo.

A ementa da disciplina aborda a conceituação, a importância, noções de gestão de negócios, planejamento estratégico e demais atributos necessários a um profissional de atitude empreendedora, buscando desenvolver competências como a atitude empreendedora e um tato mais aguçado para oportunidades de implantação de negócios bem-sucedidos. Em ambas as modalidades, a disciplina de empreendedorismo ao final do curso, na modalidade integrado, no sétimo período (penúltimo) e na modalidade subsequente, no quarto período (último período), fazem parte do conteúdo programático as seguintes temáticas: Empreendedorismo, empreendedor, negócios/ empresas, plano de negócios, etapas para abertura e regularização de empresas e Gestão de Serviços para a Terceira Idade, sendo prevista a abordagem de conceituação, características, contextualização e outros subtemas convenientes a casa temática macro.

A presente pesquisa objetiva, portanto, identificar a presença de conteúdos de educação empreendedora no Curso Técnico de Segurança do Trabalho. Visando verificar se o que é previsto nas ementas das disciplinas é concretizado em sala de aula e qual a perepção dos docentes e estudantes sobre a educação empreendedora na instituição.

Os dados apresentados são provenientes de uma pesquisa de PIBIC realizada de 2019 a 2020, inserida no projeto "Formação empreendedora, protagonismo estudantil e mudanças organizacionais em instituições de ensino brasileiras", que parte de inquietações acerca da forma com a qual o empreendedorismo vem sendo trabalhado bem como seus impactos na vida do aluno.

\section{FUNDAMENTAÇÃO TEÓRICA}

Conceituar o empreendedorismo é algo difícil de se fazer de maneira precisa e objetiva, todavia, é simples reconhecer alguns outros conceitos e atividades aos quais está associado "constata-se que algumas palavras se repetem no mundo conceitual do empreendedorismo, tais como destruição criativa, criação, construção e tomada de iniciativa" 
(JÚNIOR, et al. 2006, p.7). Dessa forma, "Considera-se, muitas vezes, o empreendedorismo como a inovação, a criatividade, a criação de novas organizações ou de algum tipo de novidade" (LIMA, et al. 2018, p. 46). Pode se manifestar na forma de criação de novos negócios, ou na reinvenção de aspectos de organizações já existentes, no setor privado está relacionado à obtenção de lucro, e no setor público, está ligado ao bem-estar do cidadão, criação de valor e legitimação.

A alcunha de empreendedor é comumente associada apenas àquele que abre uma empresa, todavia ser empreendedor relaciona-se a possuir atitude empreendedora, vale salientar que:

O Empreendedorismo requer um tipo de comportamento que inclui tomada de iniciativa, organização ou reorganização de mecanismos socioeconômicos para transformar recursos e situações em contas práticas, avaliação e aceitação de riscos e tem como principais recursos o próprio empreendedor (SOARES, BOAS e JONES, 2014, p. 3).

Dessa forma o desenvolver de diversas competências ligadas a proatividade, inovação, visão de mercado, dentre outras, caracterizam o indivíduo empreendedor. Em síntese "os empreendedores são aqueles que atuam transformando inovações em realidades de mercado" (ANDRADE e TORKOMIAN, 2001, p. 301).

Das MPEs abertas, um percentual considerável não chega ao segundo ano de funcionamento. Alguns fatores como "deficiências no planejamento antes da abertura das empresas; deficiência na gestão após a abertura do negócio; políticas insuficientes de apoio ao setor; conjuntura econômica deprimida e problemas pessoais dentre outros de menor relevância". (PEREIRA et al., 2009, p. 51) são associados ao fracasso de um empreendimento. É comum também que estes empreendedores, no ato da abertura de suas empresas, não possuam conhecimento técnico para empreender (sobre o qual discorreremos mais à frente), e que não se capacitem para gerir a empresa, somando-se à dificuldade da “captação de recursos a longo prazo e a taxas razoáveis para financiar a inovação" (PEREIRA et al., 2009, p. 57), esses fatores dificultam a obtenção de destaque no mercado, culminando no fracasso do negócio.

O perfil de profissional empreendedor "só vai prevalecer à medida que for estimulada e posta em prática, por meio da educação, a capacitação para empreender, seja na Universidade ou em qualquer outro nível de ensino" (ALMEIDA, et al., 2008, p. 68). Fomentar o empreendedorismo corporativo é uma alternativa na busca de um diferencial de 
mercado, o que pode ser decisivo na lucratividade, e até mesmo na sobrevivência da organização, então, deve-se valorizar o funcionário que busque incorporar novos métodos, práticas e mecanismos, que propõe novos projetos, dentre outras atitudes. "Na conjuntura atual de hipercompetição, encarada pelas organizações desde seus primórdios, o empreendedorismo concede poderes aos indivíduos" (RIBEIRO, ARAÚJO e OLIVEIRA, 2014, p. 309), portanto, cabe ao empreendedor, neste caso, o corporativo, ser proativo e buscar reinvenção, e à organização conceder-lhe autonomia.

As dificuldades de gestão das MPEs oriundas do despreparo de seus gestores, bem como a demanda a funcionários de atitude empreendedora evidenciam a necessidade de desenvolvimento da educação empreendedora nos diversos níveis de ensino, dessa forma:

Tendo em vista que os profissionais deverão estar preparados para o mundo do trabalho e exercício da cidadania como um trabalhador empreendedor, com visão para as oportunidades de negócios, a implementação da educação empreendedora nas escolas de educação profissional técnica e tecnológica deve basear-se no desenvolvimento de habilidades empreendedoras nos alunos (SOARES, BOAS e JONES, 2014, p. 1).

A educação empreendedora, de maneira simplificada, é caracterizada por visar desenvolver habilidades no "âmbito da identificação e aproveitamento de oportunidades e sua posterior transformação em realidade, contribuindo assim para a geração de valores financeiros, sociais e culturais para a sociedade na qual o ser humano está inserido" (ANDRADE e TORKOMIAN, 2001, p. 301).

A educação para empreender, e não sobre empreender não se encaixa perfeitamente nos moldes teóricos expositivos comumente adotados na educação brasileira, requer a incorporação de metodologias ativas, visto que "Nenhum estudante se torna protagonista de seu processo formativo apenas ouvindo aulas expositivas”(DEBALT e GOLFETO, 2016, p. 8). Deve-se permitir que o estudante aprenda fazendo, são bastante proveitosas metodologias centradas na resolução de problemas, é importante também que o docente alinhe o conteúdo à realidade na qual se insere o aluno. Debalt e Golfeto (2016) apontam O trabalho em equipe, a resolução de problemas reais e o desenvolvimento de competências pessoais e profissionais como diferenciais incorporados ao estudante que vivencia o processo de educação empreendedora.

"Dentre os recursos mais utilizados no ensino do empreendedorismo nos últimos anos, está o plano de negócios" (SCHAEFER e MINELLO, 2016, p. 71), todavia além dos conteúdos administrativos conteúdos relacionados ao desenvolvimento das competências do 
empreendedor também devem ser abarcados, o empreendedor deve ter autoconhecimento, conhecimento do setor, networking, disponibilidade de tempo, liderança e proatividade. Para que haja uma mudança de panorama educacional é necessária capacitação dos professores, que precisam estar comprometidos e dedicar porções consideráveis de tempo.

Convém discorrer acerca de algumas ferramentas utilizadas para viabilizar a criação e sobrevivência de organizações, que são úteis na educação para empreender:

a) Design Thinking: é comum que as empresas adotem modelos de negócios engessados para evitar a insegurança proveniente da implantação de novas ideias. O Design Thinking (Em português, pensar como um designer), surge como alternativa para facilitar o processo. As noções de Design Thinking surgem por volta da década de 1097, seria um modelo que concentra um conjunto de ideias voltada para a solução de problemas e busca de oportunidades, "ao integrar o desejável ponto de vista humano ao tecnológica e economicamente viável” (BROWN, 2010, p. 3);

b) Canvas: O Business Model Canvas (Quadro de modelo de negócios) é um quadro originalmente elaborado por Osterwalder e Pigneur, no qual é dividido em nove partes: Segmentos de Cliente, Proposta de valor, Canais, Relacionamento com Clientes, Fontes de Receita, Recursos Principais, Atividades-Chaves, Parcerias Principais e Estrutura de Custo; que permitem a discussão e análise sobre modelos de negócios já existentes ou novas propostas de modelos de negócios. Portanto, “o modelo de negócios caracteriza-se como uma representação abstrata dos elementos-chave da estratégia de um negócio" (VICELLI e TOLFO, 2017, p. 4);

c) Pitch: É uma apresentação sucinta e objetiva, geralmente, de até 5 minutos que visa convencer investidores a financiarem uma ideia. A origem do termo, de acordo com o SEBRAE (2017), se dá em Hollywood, quando, para conseguir apresentar suas ideias para investidores e executivos - que não teriam tempo disponível para ler roteiros por completo -, os produtores dos filmes resumiam suas histórias de forma que pudessem ser narradas durante um encontro num elevador. Dessa forma, aumentavam as chances de gerar interesse e custear a produção dos filmes. Há ainda, formatos de Pitch nos quais a apresentação deve ser feita em arquivo de texto de até 3 linhas, falado, em 30 segundos ou intervalos de tempo maiores, mas sem perder a rapidez e objetividade. É necessário apresentar o objetivo do negócio, o público, soluções e propostas, os possíveis competidores no mercado e uma projeção financeira realista;

d) Design Sprint: é um processo de cinco etapas elaborado em um certo período de tempo para tangibilizar uma ideia e sua funcionalidade. Utilizando Design Thinking, essa 
metodologia foi produzida por Jake Knapp, parceiro de design do Google Ventures, em 2010. Ao observar que o brainstorm em grupo não rendia boas discussões, o designer projetou uma nova estrutura, individual, de organização de ideias, que foi aprimorada em 2012 em conjunto com sua equipe. Esse tipo de Sprint (metodologia ágil) serve para otimizar um ciclo completo de desenvolvimento de um produto. Desta forma, obtêm-se rapidamente os feedbacks da construção, fazendo reflexões críticas do negócio através de design, prototipagem e testes com os usuários. Os cinco passos do Design Sprint são:

- Unpack: Projeção da ideia;

- $\quad$ Sketch: Esboço das soluções;

- Decide: Escolha da única solução;

- Prototype: Prototipação;

- Test: Apresentação ao usuário e coleta de feedback.

Ao final do processo, é realizado uma discussão com base nas informações adquiridas para a equipe avaliar o projeto.

e) Lean startup: A palavra lean pode ser traduzida como "enxuta", então, Lean startup significa, numa tradução livre, startup enxuta. Esse conceito, no universo da administração, envolve um trabalho de identificação e eliminação de desperdícios nos processos e está muito atrelado ao ambiente de startups de tecnologia. (ENDEAVOR, 2015). Em 2011, o americano Eric Ries, pesquisador da Harvard Business School, adaptou essa metodologia unindo novos conceitos, como o MVP (Mínimo Produto Viável), a ideia de pivot e métodos mais ágeis de interação com clientes. Na prática, esse método apoia-se em três pilares:

- Canvas: Formar um diagrama, evitando longos relatórios;

- Customer development: Montar MVP (Mínimo Produto Viável) - “uma versão simplificada do seu produto, com suas principais funcionalidades" (SEBRAE, 2019) - e coletar opinião dos potenciais usuários;

- “Desenvolvimento ágil”: Utilizando o feedback adquirido, desenvolver o produto.

Empresa Júnior é uma associação civil sem fins lucrativos, e que tem como objetivo formar jovens empreendedores capazes de inovar e impactar, além disso "a empresa júnior contribui ativamente para o desenvolvimento da sociedade a qual está inserida, oferecendo serviços de baixo custo para a comunidade local” (SEBRAE, s.d.). Essas organizações trabalham com três clientes principais:

- Os alunos;

- As empresas; 


\section{PRESENÇA DE CONTEÚDOS DE EDUCAÇÃO EMPREENDEDORA NO CURSO DE}

- As universidades.

Com a necessidade da aplicação de seus aprendizados, os estudantes de uma universidade francesa, em 1967, fundaram a primeira Empresa Júnior, na cidade de Paris. Esse ideal foi difundido por toda Europa, até que em 1987 chegou em solo brasileiro, na maior cidade do Brasil, São Paulo, por alunos de administração da Fundação Getúlio Vargas é fundada a primeira Empresa Júnior do país. Hoje, em 2019, o Brasil apresenta o maior Movimento de Empresas Júniores no mundo. (VALÉRIO, 2019)

Startup, por sua vez, é uma empresa jovem com um modelo de negócios repetível e escalável, em um cenário de incertezas e soluções a serem desenvolvidas (STARTSE, 2016). As Startups transformam processos a partir da busca da inovação, o que estimula o olhar para o futuro.

Em sua etimologia, Startup sempre foi sinônimo de iniciar algo. O termo começou a ser utilizado durante a crise das empresas ponto-com, entre 1996 e 2001.

As Startups podem ser divididas em:

- $\quad$ B2B (Business to Business): Negócios para negócios. Empresa que atende outras empresas;

- B2C (Business to Consumer): Negócios para consumidores. Fornecedor de serviço para o consumidor final;

- B2B2C (Business to Business to Consumer): Negócios para empresas para consumidores. Acordo entre empresas visando uma venda para o cliente final.

As Startups transformam processos a partir da busca da inovação, o que estimula o olhar para o futuro.

\section{METODOLOGIA}

A pesquisa é caráter exploratório, pois objetiva sintetizar uma visão panorâmica de um tema pouco explorado, "tendo em vista a formulação de problemas mais precisos ou hipóteses pesquisáveis para estudos posteriores" (GIL, 2006, p.27),descritivo, buscando descrever alguns fenômenos e identificar as relações existentes entre eles, localizando variáveis pertinentes, contando com a "utilização de técnicas padronizadas de coleta de dados" (GIL, 2006, p.28), sendo também uma pesquisa de campo uma vez que o método "consiste na observação de fatos e fenômenos tal como ocorrem espontaneamente" (MARCONI e LAKATOS, 2003, p. 186).

O campo de Pesquisa será constituído pelo Campus Recife do IFPE, por ofertar o Curso Técnico Segurança do Trabalho. Os sujeitos de pesquisa serão os estudantes do Curso 
Técnico de Segurança do Trabalho, das modalidades Ensino Médio Integrado ao Técnico e Subsequente e os Professores que lecionam disciplinas ligadas ao empreendedorismo no Curso Técnico de Segurança do Trabalho.

Utilizamos documentos oficiais do IFPE, relativos ao Plano de curso do Curso Técnico de Segurança do Trabalho, conteúdos programáticos de determinadas disciplinas e documentos norteadores institucionais e questionários. Utilizamos também software de planilha para tabulação de dados e produção de gráficos.

A pesquisa foi realizada em três momentos: o primeiro destinado à análise documental, utilizando documentos do IFPE relativos ao plano de curso do Curso Técnico de Segurança do Trabalho, conteúdos programáticos das disciplinas presentes nas duas modalidades do curso, e documentos norteadores institucionais.

O segundo consistiu na aplicação de entrevista semiestruturada junto aos professores das disciplinas relacionadas ao empreendedorismo, e aplicação de questionário com os estudantes do curso, para que seja feita uma triangulação dos dados obtidos nas três coletas de dados de forma a verificar como tem sido executado o que é previsto nas normativas da instituição. Em seguida, na última etapa os dados obtidos foram tabulados e suas correlações analisadas.

\section{RESULTADOS E DISCUSSÃO}

Dentre os 13 docentes, da área de Gestão que Lecionam no IFPE - Campus Recife, 7 responderam ao questionário elaborado. Nossa amostra, portanto, representa 53,84\% do universo.

Quanto ao tempo de atividade docente, classificaremos como recentes, respectivamente, com até quinze anos e acima de quinze anos de atividade docente no IFPE. Três antigos, com 23, 23 e 22 anos, e quatro mais recentes, com 15, 14, 8 e 6 anos. Observamos uma conduta mais tradicional quanto às metodologias de ensino utilizadas pelos docentes mais antigos se comparados aos mais recentes.

$\mathrm{O}$ fato de que entre os mais recentes todos possuem experiência com Empresas Juniores, Incubadoras, Aceleradoras ou Startups, enquanto com os mais antigos ocorre justamente o contrário, nenhum deles possui experiência, nos permite inferir que a postura quanto às metodologias de ensino têm relação com o processo formativo ao qual foram submetidos. As empresas júniores começam a surgir no Brasil por volta de 1987, as incubadoras também começam a surgir na década de 1980, quanto às Startups, no início da década de 1990, já quando falamos de aceleradoras, seu surgimento ocorre já nos anos 2000. 
No artigo 87 da Lei $n^{\circ}$ 8.112/90, é estabelecido que “Após cada quinquênio de efetivo exercício, o servidor poderá, no interesse da Administração, afastar-se do exercício do cargo efetivo, com a respectiva remuneração, por até três meses, para participar de curso de capacitação profissional". No cumprimento dessa lei, os servidores do IFPE, possuem plenas condições de, cumprindo as condições estabelecidas, realizar capacitações para se atualizar, visando melhorias na atividade que exercem. No entanto, quando perguntados se o IFPE estimula e oferta capacitação na área para os docentes apenas 2 afirmaram que sim. Sabendo que oferta, inferimos que as respostas negativas se dão por não reconhecerem estimulo à capacitação dos profissionais, bem como por desconhecimento das normativas que norteiam o funcionamento da instituição. O processo de capacitação e atualização docente nas novas tendências de mercado é apontada pela maioria dos voluntários (6) como iniciativa própria, utilizando de cursos de pós-graduação, cursos livres e conteúdo disponível na mídia tradicional e internet, um deles relata ter utilizado o recurso de licença capacitação.

As disciplinas que englobam temáticas de educação empreendedora presentes na matriz curricular dos cursos técnicos do IFPE, Relações Humanas e Trabalho e Empreendedorismo são ofertados nos períodos finais dos cursos. Cinco dos respondentes consideram adequada a disposição das disciplinas por julgarem que demanda maior maturidade do estudante e por verem como algo complementar ao conhecimento técnico que o estudante já teria adquirido, comentam ainda que facilitaria a aplicação prática dos princípios do empreendedorismo, das competências empreendedoras na área específica de formação.

Todavia consideramos a educação empreendedora como algo transversal e interdisciplinar, que deve transpassar os aprendizados das diferentes temáticas/disciplinas que compõem a formação do profissional. Portanto, sendo essas disciplinas dispostas ao final do curso resta pouco tempo para o desenvolvimento e vivência da educação empreendedora no ambiente acadêmico. Se educados para empreender do início ao fim do processo formativo, a capacidade do estudante de aplicar em distintas áreas e o desenvolvimento de suas competências empreendedoras seriam impulsionados em função do constante trabalho em torno desses elementos.

É uma unanimidade entre os inquiridos a opinião de que disciplinas de educação empreendedora deveriam estar presentes na educação básica e superior. As justificativas apresentadas se alinham com a crescente tendência de mercado de dar preferência à contratação de funcionários que apresentam competências empreendedoras.

Apontam ser uma tendência de mercado a busca por profissionais com postura empreendedora deve ser compromisso dos docentes prepará-los para o cenário. Há ainda o 
apontamento para o fato de que muitos recorrem ao empreendedorismo, no sentido de criar uma empresa, como alternativa para a inserção no mercado de trabalho por pura necessidade, e que estes precisam estar preparados para reconhecer boas oportunidades, alinhando, assim, necessidade e oportunidade, maximizando as chances de sucesso de um possível empreendimento.

Não verificamos a existência de atividades entre duas ou mais disciplinas de conteúdo específico que envolvam a construção de produtos/serviços/negócios juntamente com a disciplina de empreendedorismo no curso de Segurança do Trabalho.

Todos os participantes da pesquisa apontam que é comum que os estudantes considerem abrir um negócio próprio como alternativa profissional. Cinco deles verificam impacto positivo da preparação que tiveram na instituição na vida dos egressos de segurança do trabalho. Destacam o sucesso de empresas de consultoria e serviços na área.

Quando perguntados sobre seus maiores desafios como docentes de educação empreendedora no IFPE 4 deles tomam a responsabilidade para si: mencionam a dificuldade de fomentar no estudante o desejo pela atitude empreendedora; tornar a disciplina atrativa e viável para a realidade dos estudantes; alinhar a prática da disciplina com a necessidade da carreira de cada curso e, desafiar o status quo e estimular a iniciativa e motivação do aluno. Os demais, que projetam no outro a responsabilidade, apontam para a falta de uma incubadora no Campus Recife e a desvalorização das disciplinas em questão por parte da instituição e dos estudantes.

No tópico VIII do artigo $6^{\circ}$ da seção II da lei 11892, de 29 de dezembro de 2008, é colocado que os IFs têm, dentre suas finalidades, a incumbência de "realizar e estimular a pesquisa aplicada, a produção cultural, o empreendedorismo, o cooperativismo e o desenvolvimento científico e tecnológico". Os docentes voluntários identificam que, fazendo cumprir o que é previsto em lei, há, dentro do IFPE - Campus Recife, iniciativas como o Ciclo de Palestras "A Gestão no todo", o núcleo de empreendedorismo, o Programa Institucional de Bolsas de Iniciação Científica (PIBIC) e o Programa Internacional Despertando Vocações (PDV), que fomenta atividades de Pesquisa e Extensão. Dois dos voluntários apontam ainda desconhecerem iniciativas no tocante à temática.

No que se refere às metodologias de ensino para a educação empreendedora, Debalt e Golfeto (2016), Schaefer e Minello (2016) apontam para uma incompatibilidade com o modelo totalmente expositivo e salientam a necessidade de metodologias ativas e participativas, direcionando para a resolução de problemas reais, colocando o aluno no centro do processo. Os recursos que os voluntários relatam utilizar giram em torno de seminários, 
planos de negócios, participação em eventos científicos, dinâmicas de grupo e aulas expositivas.

Quanto a ferramentas que viabilizam metodologias ativas como Design Thinking, Canvas, Pitch, Design Sprint, Lean Startup e resolução de problemas reais, somente 3 dos inquiridos são adeptos. Somente 2 deles costumam realizar visitas a empresas.

Obtivemos 36 respondentes aplicação do questionário junto aos estudantes do Curso Técnico de Segurança do Trabalho. Traçando o perfil econômico, obtivemos que nossa amostra é composta 67 por cento por mulheres, e os 33 por cento restantes por homens. A distribuição etária se dá da seguinte maneira: 25\% de 13 a 16 anos, 53\% de 17 a 20 anos, 14\% de 21 a 24 anos, 3\% de 24 a 27 anos, e 5\% acima de 27 anos. Do total de voluntários, 69\% (25 voluntários) cursam na modalidade Médio Integrado ao Técnico, destes, 22 no turno matutino e 3 no turno vespertino, e $31 \%$ (11) na modalidade Subsequente, desses 1 no turno matutino, 3 no turno vespertino e 7 no turno noturno. Possuem renda familiar de até 1 salário mínimo 44\% dos voluntários, entre 1 e 3 salários mínimos, 25\% deles, de 3 a 6 salários mínimos, 25\%, e os 6\% restantes, de 6 a 9 salários mínimos. Metade (50\%, 18 voluntários) dos estudantes são cotistas, evidentemente, a outra metade não é cotista. Dentre os cotistas, $22 \%$ (4) são brancos, $56 \%$ (10) são pardos, $5 \%$ (1) são negros, $17 \%$ (3) são afrodescendentes. E dentre os não cotistas, $67 \%$ (12) são brancos, $28 \%$ (5) pardos, e 5\% (1) afrodescendentes. De todos os estudantes, $56 \%$ (20) falam ao menos uma língua além da língua vernácula, e os $44 \%$ (16) restantes falam apenas português. Apenas $8 \%$ (3) dos voluntários trabalha ou exerce atividade acadêmica não remunerada.

Num panorama geral, é um consenso entre autores como Soares, Boas e Jones (2014), Andrade e Torkomian (2001) e Drucker (1985) caracterizar o sujeito empreendedor como aquele que possui competências relacionadas à capacidade de inovar, trabalhar em equipe, proatividade, dinamismo, etc. Nesse âmbito, solicitamos uma autoanálise dos voluntários quanto a algumas afirmações elencadas:

a) Sou uma pessoa inovadora;

b) Gosto de trabalhar com outras pessoas;

c) Gosto de ajudar as pessoas;

d) Gosto de ir a palestras/ cursos/ oficinas fora do ambiente escolar;

e) Gosto de participar de projetos dentro do IFPE;

f) Gosto de desenvolver novos trabalhos;

g) Sou uma pessoa dinâmica.

Verificamos, num panorama geral, que parte significativa dos participantes da 
pesquisa reconheceu em si competências empreendedoras. Temos que 11 dos voluntários respondeu em concordância com todas as afirmações feitas, representando 30,5\% da amostra.

Partindo para questões mais objetivas em relação ao processo formativo no tocante à Educação Empreendedora, quando perguntados sobre o conceito de Educação Empreendedora, somente $36 \%$ deles sabe o que significa.

Fazendo cumprir o que determina o tópico VIII do artigo $6^{\circ}$ da seção II da Lei 11.892, de 29 de dezembro de 2008, Lei que institui a Rede Federal de Educação Profissional, Científica e Tecnológica, em todos os cursos técnicos do IFPE está presente a disciplina de Empreendedorismo. Ainda assim, 8\% (3) dos voluntários responderam que não há uma disciplina de empreendedorismo em seus cursos, e 42\% (15) responderam não saber se há. Dos 50\% (18) restantes, metade já cursaram a disciplina, e sobre a experiência, 67\% (6) classificam-na como positiva, pelo fato de terem se relacionado com o mundo real e os ajudado a pensar em empreender; $22 \%$ (2) consideram que se tivesse sido ofertada no início do curso poderia ter lhes auxiliado a compreender como fazer o conhecimento técnico se transformar em uma oportunidade de negócio; e 11\% (1) não considera nenhum dos dois pontos de vista elencados anteriormente.

Uma porção considerável dos voluntários, 78\% (28), afirma já ter pensado em empreender, desenvolver algum produto ou serviço. Um pouco menos da metade dos voluntários, 47\% (17), afirma já ter participado de atividades de outras disciplinas que precisassem de conhecimentos de empreendedorismo, percentual que supera o de estudantes que já cursaram a disciplina, o que corrobora com a ideia de que a disciplina deveria estar presente na educação básica e, nesse caso específico, seria mais proveitosa se cursada nos semestres iniciais do curso técnico.

No que tange às metodologias de ensino, iniciamos elencando algumas ferramentas solicitando que selecionassem aquelas que julgam benéficas, (direta ou indiretamente) ao seu desenvolvimento acadêmico ou pessoal, obtivemos que:

- Conceitos e teoria bem explicados em sala de aula, monitoria em ensino, trabalhos de casa propostos em sala de aula, discussões em grupo em sala de aula, jogos pedagógicos em sala de aula, visitas técnicas; são considerados por 39\% (14);

- Projetos de extensão, olimpíadas do conhecimento (OBMEP, OBA etc.), olimpíadas esportivas, campeonatos, expressões artísticas (participar em bandas, orquestras, etc); são considerados por $33 \%(12)$;

- Empresas Juniores, hackathons, grêmio estudantil, cursos/estudos extracurriculares, participação voluntária em ONG's e projetos de caridade, ações religiosas. ão 
considerados por $14 \%(5)$;

- Congressos Científicos PIBIC -Iniciação Científica, monitorias em eventos escolares (Mais Campus, SNCT, etc). são considerados por 11\% (4);

- E 3\% (1) não considera nenhuma das alternativas anteriores.

Da totalidade, 36\% (13) afirma não ter vivenciado as experiências relatadas no item anterior. Quando perguntados sobre a frequência com a qual seus professores recomendam atividades/experiências, como as relatadas anteriormente, obtemos o seguinte resultado:

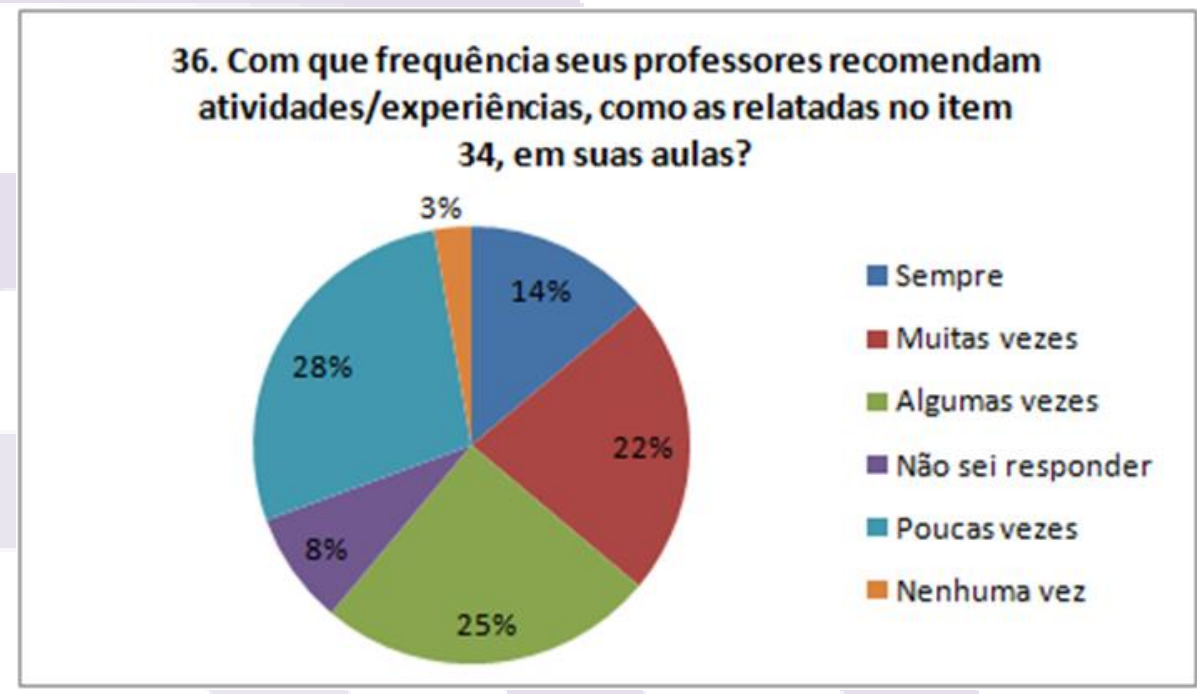

Gráfico 01: gráfico referente à frequência da recomendação de atividades dinâmicas por parte dos professores .

Fonte: Própria (2020).

\section{CONCLUSÕES}

Identificamos a presença de conteúdos de educação empreendedora em todos os cursos técnicos do IFPE, portanto, estão presentes no curso Técnico em segurança do Trabalho. Esses conteúdos são ministrados nas disciplinas de Empreendedorismo e Relações Humanas e Trabalho.

Verificamos a necessidade de incentivar o uso de metodologias ativas para fortalecer o interesse dos estudantes e pela temática bem como o aproveitamento dos conteúdos apresentados.

Salientamos também a observação de que essas disciplinas poderiam ter uma introdução nos primeiros períodos dos cursos, pois faria com que alguns dos estudantes encarassem os conteúdos específicos do curso com uma visão mais proativa, amparados na mentalidade empreendedora, identificando oportunidades e aplicações dos seus 
conhecimentos ao longo do curso.

Dessa forma, é importante, também, que haja continuidade no apoio e incentivo para iniciativas de fomento ao empreendedorismo e a cultura empreendedora.

\section{REFERÊNCIAS}

ALMEIDA, Kátia et al. A influência do ensino do empreendedorismo no potencial empreendedor do aluno. Revista de Negócios, Blumenau, v. 13, n. 2, pp. 67-76, Abr./Jun. 2008.

ANDRADE, Renato; TORKOMIAN, Ana. Fatores de influência na estruturação de programas de educação empreendedora em instituições de ensino superior. In: Encontro de Estudos sobre Empreendedorismo e Gestão de Pequenas Empresas, II, 2001, Londrina, Anais, Londrina - PR, 2001, p. 299-311.

BICUDO, Lucas. O que é uma startup? StartSe, 3 de maio de 2016. Disponível em: < https://www.startse.com/noticia/startups/afinal-o-que-e-uma-startup >. Acesso em: 02 de out. de 2020.

BRASIL. Lei n. ${ }^{\circ}$ 8112, de 11 de dezembro de 1990. Dispõe sobre o regime jurídico dos servidores públicos civis da União, das autarquias e das fundações públicas federais. Brasília, DF: Presidência da república [1990]. Disponível em: http://www.planalto.gov.br/ccivil_03/leis/18112cons.htm. Acesso em: 30 set. 2020.

BRASIL. Lei n. ${ }^{\circ}$ 11982, de 29 de dezembro de 2008. Institui a Rede Federal de Educação Profissional, Científica e Tecnológica, cria os Institutos Federais de Educação, Ciência e Tecnologia, e dá outras providências. Brasília, DF: Presidência da república [2008]. Disponível em: http://www.planalto.gov.br/ccivil_03/_ato2007-2010/2008/lei/111892.htm. Acesso em: 30 set. 2020.

BROWN, Tim. Design Thinking: uma metodologia poderosa para decretar o fim das velhas ideias. Rio de Janeiro. Elsevier, 2010.

DEBALD, Blasius; GOLFETO, Norma. Protagonismo estudantil e metodologias ativas de aprendizagem em tempos de transformação na educação superior. Revista Científica Eletrônica do Centro Universitário Uniamérica, v. 10, n. 20, pp. 05-11, Jul./Dez. 2016.

DRUCKER, Peter. Inovação e espírito empreendedor. 2 ed. São Paulo: Pioneira, 1987;

GIL, Antonio. Métodos e técnicas de pesquisa social. $6^{\circ}$ ed. São Paulo. Câmara brasileira do livro: 2008.

GITAHY, Yuri. Lean Startup e MVP: entendendo e aplicando os conceitos. SEBRAE, 27 de set. $\quad 2019 . \quad$ de Disponível em: https://www.sebrae.com.br/sites/PortalSebrae/artigos/artigosInovacao/entenda-o-que-e-leanstartup,03ebb2a178c83410VgnVCM1000003b74010aRCRD >. Acesso em: 02 de out. de 2020.

JÚNIOR, J.B.C. et al. Empreendedorismo e educação empreendedora: confrontação entre a 
teoria e prática. Revista de Ciências da Administração, Santa Catarina, v. 8, n. 15, jan./jun. 2006.

LIMA, Simone et al. Empreendedorismo público e orientação empreendedora em instituições federais de ensino. Revista de Ciências da Administração, Florianópolis, v. 20, n. 50, pp. 44-60, Abr. 2018.

MARCONI, Marina; LAKATOS, Eva. Fundamentos da metodologia científica. 5. ed. São Paulo: Editora Atlas S.A., 2003.

MPEs respondem por 30\% do PIB brasileiro. Diário do Comércio, Belo Horizonte, 09, abril de 2020. Economia. Disponível em: < https://diariodocomercio.com.br/economia/mpesresponden-por-30-do-pib-brasileiro/amp/>. Acesso em: 02 de outubro de 2020.

O lean startup te ajuda a validar seu modelo de negócio. Endeavor Brasil, 23 de jul. de 2015. Disponível em: < https://endeavor.org.br/estrategia-e-gestao/lean-startup/ > . Acesso em: $02 \mathrm{de}$ out. 2020.

PEREIRA, Mauricio et al. Fatores de inovação para a sobrevivência das micro e pequenas empresas no Brasil. Revista de Administração e Inovação, São Paulo, v. 6, n. 1, pp. 50-65, 2009.

PEREIRA, Paulo. Pitch, o desafio constante de vender um negócio. SEBRAE, 11 de out. de 2017. Disponível em: <https://blog.sebrae-sc.com.br/pitch/>. Acesso em: 02 out 2020.

RIBEIRO, Ricardo; OLIVEIRA, Edson; ARAUJO, Elvira. A contribuição das instituições de ensino superior para a educação empreendedora. Revista Brasileira de Gestão e Desenvolvimento Regional, Taubaté, v. 10, n. 3, pp. 295-313, set. 2014.

SCHAEFER, Ricardo; MINELLO, Italo. Educação empreendedora: premissas, objetivos e metodologias. Revista Pensamento Contemporâneo em Administração, Rio de Janeiro, v. 10, n. 3, pp. 60-81, jul./set. 2016.

SOARES, Mônica; BOAS, Ana; JONES, Graciela. Práticas de Difusão da Educação Empreendedora Pelos Docentes de um Curso Técnico em Agropecuária. In: Simpósio de Excelência em Gestão e Tecnologia, XI, 2014, Anais, 2014, p. 1-17.

VALÉRIO, Vitor. Qual a diferença entre Startup e Empresa Júnior?. Select, 19 de out. de 2019. Disponível em: <https://www.select.eng.br/2019/10/19/qual-a-diferenca-entre-startupe-empresa-junior/>. Acesso em: 02 de out de 2020.

VICELLI, Bruno; TOLFO, Cristiano. Um estudo sobre valor utilizando o Business Model Canvas. Revista Espacios, Caracas, v. 38, n. 3, pp. 14-27, 2017. 